\title{
La resistencia de los trabajadores a la última dictadura militar. Un aporte a su conceptualización
}

\section{Worker resistance to the last military dictatorship. A contribution to its conceptualization}

\author{
Daniel Dicósimo \\ Instituto de Estudios Históricos-Sociales \\ Universidad Nacional del Centro de la Provincia de Buenos Aires \\ (Argentina) \\ daniel.dicosimo@speedy.com.ar
}

\section{Resumen}

El objetivo de este artículo es repensar el concepto de "resistencia" como sinónimo de conductas no consensuales de los trabajadores durante el período de la última dictadura cívico-militar en la Argentina, tanto respecto a las políticas económicas y laborales de la misma como a las directivas patronales en el lugar de trabajo. En los estudios existentes es común encontrar una definición flexible de resistencia que comprende algunas formas de comportamientos no consensuales hacia aquella última. Esto tiene una ventaja que consiste en desmitificar dichas conductas, pero no es del todo inclusiva ya que quedan afuera las actitudes propias del "escape" o la "obediencia condicionada." En este artículo nos proponemos evaluar distintas alternativas conceptuales, que nos acerquen a resolver este problema, considerando algunos de los textos clásicos y los aportes más recientes sobre el tema.

Palabras Clave: Resistencia - Trabajadores - Dictadura 


\begin{abstract}
The objective of this article is to rethink the concept of "resistance" as a synonymous of non-consensual behaviors undertaken by workers during the last period of civic-military dictatorship in Argentina. This includes both acts taken against the economic and labor policies as well as the employer policies in the workplace. In the existing studies, we found flexible definitions of "resistance" as forms of non-consensual behaviors. This involves an advantage: to demystify these behaviors. However, it has also a disadvantage: it does not include attitudes of "escape" or "conditional obedience". In this article we propose to evaluate different conceptual alternatives that bring us closer to solving this problem. We will consider both classical texts as well as the most recent contributions on the topic.
\end{abstract}

Key Words: Resistance - Workers - Dictatorship

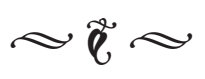

\section{Introducción}

El objetivo de este artículo es repensar el concepto de resistencia como sinónimo de conductas no consensuales de los trabajadores durante el período de la última dictadura cívico-militar en la Argentina, tanto respecto a las políticas económicas y laborales de la misma como a las directivas patronales en el lugar de trabajo. En los estudios históricos existentes es común encontrar una definición flexible de resistencia que comprende algunas formas de comportamientos no consensuales hacia esta última. Esto tiene una ventaja que consiste en desmitificar dichas conductas, pero no es del todo inclusiva ya que quedan afuera las actitudes propias del "escape" o la "obediencia condicionada." En este artículo nos proponemos evaluar distintas alternativas conceptuales, que nos acerquen a resolver este problema, considerando algunos de los textos clásicos y los aportes más recientes sobre el tema.
La última dictadura militar en Argentina se caracterizó, entre otras cosas, por realizar un gran esfuerzo disciplinador en los campos laboral y sindical, con el propósito de neutralizar un sector popular organizado y activado políticamente. Desde los primeros gobiernos peronistas una clase obrera "indisciplinada", con fuerte identidad política y un movimiento sindical poderoso, habían frustrado los intentos de modernización económica de gobiernos civiles y militares. ${ }^{1} \mathrm{Si}$ en el pasado los militares habían valorado el encuadramiento político $\mathrm{y}$ sindical de los trabajadores como un dique

1. O’DONNELL, Guillermo, Modernización y autoritarismo, Paidós, Buenos Aires, 1972. Para las preocupaciones de los empresarios sobre la disciplina laboral ver: SIMONASSI, Silvia, "Productividad y disciplina en las fábricas metalúrgicas del Gran Rosario: Una mirada desde el periódico de la Asociación de Industriales Metalúrgicos de Rosario, 1974-1981”, en Papeles de trabajo, Rosario, 1996, № 3 y SIMONASSI, Silvia, "Conflictividad laboral y políticas disciplinarias en la industria metalúrgica de la ciudad de Rosario, 19731976”, en Anuario IEHS, Tandil, 2007, № 22. 
contra el comunismo, en 1976 su perspectiva era otra: la politización radical de los jóvenes y la aparición de un sindicalismo combativo con el Cordobazo (1969) parecían advertir que el peronismo también podía ser un caldo de cultivo para ideologías "subversivas". ${ }^{2}$

Sin embargo, la respuesta del Estado a estos nuevos desafíos, que se agravaron con la militarización que algunas agrupaciones de izquierda imprimieron a su acción sindical en las fábricas, comenzó antes del golpe de 1976. ${ }^{3}$ Agitando los fantasmas de la "guerrilla industrial" y de un "complot" contra la industria pesada, el gobierno de Isabel Martínez de Perón puso en práctica una represión extrema, con asesinatos y secuestros de dirigentes y activistas sindicales combativos. En esta perspectiva, la "guerra contra la subversión" en las fábricas desencadenada después del 24 de marzo de 1976 no fue un fenómeno totalmente inédito sino un salto cualitativo y cuantitativo con respecto al ensayo de los dos años previos.

El uso del terror estatal y para-estatal en el mundo del trabajo era, en la visión de los militares y empresarios golpistas, una condición necesaria para llevar a cabo con éxito un proyecto más integral, que perseguía "refundar el ethos de la sociedad: restablecer una concepción economicista, individualista y atomista de la ciudadanía y de la vida social, la primacía de lo jerárquico y competitivo por sobre lo solidario, reemplazar con un Estado

2. NOVARO, Marcos y PALERMO, Vicente, $L a$ dictadura militar 1976-1983. Del golpe de Estado a la restauración democrática, Paidós, Buenos Aires, 2003.

3. BASUALDO, Victoria y LORENZ, Federico, "Trabajadores en la década del setenta en Argentina: perspectivas y propuestas a partir de dos estudios de caso", ponencia presentada en X Jornadas Interescuelas y Departamentos de Historia, Rosario, 2005. 'subsidiario' a aquél concebido como garante de derechos sociales, planificador y regulador del capitalismo". ${ }^{4}$ Las medidas draconianas de la dictadura formaban parte de la "Estrategia Nacional Contrasubversiva", adoptada por los mandos militares en septiembre de 1975 y pensada para lo que se consideraba una guerra. Aunque hoy en día es injustificable considerar que en la coyuntura previa al golpe de estado se desarrollaba un conflicto bélico, el ejército encontró en esa supuesta guerra el objetivo y la legitimación del régimen autoritario. ${ }^{5}$

La ofensiva militar contra los delegados y las comisiones internas identificadas como "delincuentes subversivos" fue justificada por la supuesta existencia de una "guerrilla industrial" o "terrorismo de empresa", que había ganado notoriedad a partir de la campaña de las organizaciones armadas para insertarse en los lugares de trabajo, entre 1974 y 1975. En consecuencia, el ejército ocupó las fábricas donde existían comisiones internas activas y persiguió sistemáticamente a sus miembros, instalando allí mismo centros de inteligencia, redes de informantes y lugares clandestinos de detención y tortura. ${ }^{6}$ La libertad con que actuó

4. NOVARO, Marcos y PALERMO, Vicente, $\mathrm{La}$ dictadura militar..., Op. Cit., p. 37.

5. ÁGUILA, Gabriela, Dictadura, represión y sociedad en Rosario, 1976/1983. Un estudio sobre la represión y los comportamientos y actitudes sociales en dictadura, Prometeo, Buenos Aires, 2008.

6. Sobre los operativos militares contra la organización sindical en las fábricas y la persecución, arresto y desaparición de delegados, activistas y dirigentes sindicales combativos puede leerse: CIEZA, Daniel, El componente anti sindical del Terrorismo de Estado, Cuadernos del Archivo Nacional de la Memoria No 3, Ministerio de Justicia y Derechos Humanos de la Nación, Buenos Aires, 2012; LORENZ, Federico, Los zapatos de Carlito. Una historia de los trabajadores navales de Tigre en la década del setenta, Norma, Buenos 
en ese espacio pone en evidencia que tuvo la colaboración activa de muchos empresarios. ${ }^{7}$ Tanto si hubo o no complicidad en la represión, las empresas aprovecharon la oportunidad de recuperar el control absoluto sobre sus establecimientos, sus planteles obreros y la producción.

A ello contribuiría el ataque de la dictadura contra el movimiento sindical y la legislación antiobrera y antisindical que elaboró durante el período. En las primeras horas de la madrugada del 24 de marzo de 1976, se desplegó un inmenso operativo militar, en algunos lugares ya había comenzado antes de la medianoche, destinado a detener a los dirigentes de la Confederación General del Trabajo (CGT), las 62 Organizaciones Peronistas (62 OP) y los sindicatos. En una orden secreta del comando del Ejército, emitida en febrero de ese año, los sindicalistas no identificados con las izquierdas habían sido clasificados como "enemigos potenciales". Las detenciones, por lo tanto, estaban justificadas bajo el cargo de corrupción.

Aires, 2007; BARRAGÁN, Ivonne, "Para el bien de la Nación. Gestión militar de empresas estatales, prácticas de integración y represión de la fuerza de trabajo desde la perspectiva de caso. El Astillero Río Santiago, 1973-1976", en Avances del Cesor, Rosario, 2013, No 10. Disponible en: <http://web2.rosario-conicet.gov. ar/ojs/index.php/AvancesCesor/article/view/v10a03>; BITRÁN, Rafael y SCHNEIDER, Alejandro, "Dinámica social y clase trabajadora durante la dictadura militar de 1976-1983. Estudio de la zona norte del Gran Buenos Aires en particular de las fábricas Del Carlo y Ford Motors", en RODRÍGUES, Leoncio Martins y otros, Nuevas tendencias en el sindicalismo: Argentina y Brasil, Biblos - Simón Rodríguez, Buenos Aires, 1992; BASUALDO, Victoria, "Complicidad patronal-militar en la última dictadura argentina: los casos de Acindar, Astarsa, Dálmine-Siderca, Ford, Ledesma y Mercedes Benz", en Suplemento especial Revista Engranajes, Buenos Aires, 2006, No 5, FETIA.

7. BASUALDO, Victoria, "Complicidad patronal...", Op. Cit.
No eran considerados un enemigo inmediato para los golpistas y su encarcelamiento, en algunos casos durante varios años, perseguía el objetivo de neutralizarlos y de poner en evidencia ante la sociedad, y en particular ante los trabajadores, hasta dónde estaban dispuestos a llegar los militares para garantizar el éxito del nuevo régimen. ${ }^{8}$

A la detención de dirigentes "moderados", le siguió, en la búsqueda de disciplinar al sindicalismo, la intervención de algunas de sus principales organizaciones. Desde el primer día del nuevo régimen, una serie de órdenes de la Junta Militar y de resoluciones del Ministerio de Trabajo dispusieron la designación de interventores militares a cargo de la CGT $\mathrm{y}$ de unos cuarenta sindicatos. Asimismo se disolvieron las 62 OP. Entre los gremios más relevantes intervenidos estaban la Unión Obrera Metalúrgica de la República Argentina, la Unión Obrera de la Construcción de la República Argentina, la Asociación Obrera Textil, el Sindicato de Mecánicos y Afines del Transporte Automotor, la Federación de Obreros y Empleados de la Industria Azucarera, la Unión Ferroviaria, la Asociación Bancaria de la República Argentina, entre otros.

Por otra parte, la actividad de las organizaciones no intervenidas quedaba limitada a la administración de las obras sociales, se prohibían las asambleas, huelgas y negociaciones salariales, y el mandato de sus autoridades estaba sujeto a la prórroga que otorgaba el Ministerio de Trabajo. La renovación de la misma, cuando se cumplía el plazo de vigencia del mandato,

8. NOVARO, Marcos y PALERMO, Vicente, $\mathrm{La}$ dictadura militar..., Op. Cit., p. 22. 
estaría condicionada a un comportamiento "responsable" respecto de la producción, dócil ante la autoridad empresaria y complaciente frente al régimen militar. En los primeros seis meses del régimen militar, el marco normativo e institucional de funcionamiento del sindicalismo fue alterado unilateralmente, con la derogación, la suspensión y la reforma de las leyes laborales fundamentales, como la de Contrato de Trabajo, Convenciones Colectivas, Asociaciones Profesionales y obras Sociales. ${ }^{9}$

El cambio en el equilibrio de poder en los lugares de trabajo se manifestó inmediatamente en la aplicación de una serie de medidas elementales de disciplina, con el objetivo de disminuir radicalmente el ausentismo, el incumplimiento de horarios, el "vagabundeo" dentro y fuera de la planta, etc. Si bien esas medidas provocaron un aumento inmediato de la productividad, la recuperación del "poder de dirección" fue aprovechado por los empresarios para realizar cambios más profundos en la organización del trabajo, revirtiendo avances recientes de los trabajadores en materia de seguridad e higiene, regímenes especiales de horarios y remuneraciones o removiendo obstáculos más antiguos y resistentes a la intensificación del trabajo, como la jornada laboral de ocho horas o las pausas para el descanso. ${ }^{10}$

9. Ver detalle en FERNÁNDEZ, Arturo, Las prácticas sociales del sindicalismo, Centro Editor de América Latina, Buenos Aires, 1984, p. 60.

10. Sobre la contraofensiva patronal ver GRESORES, Gabriela, "Conflictos obreros en la industria frigorífica bajo la dictadura militar: La huelga larga de Swift de Berisso", en Ciclos, Buenos Aires, 2001, Año XI, V. IX, No 22; ABÓS, Álvaro, Las organizaciones sindicales y el poder militar (1976-83), CEAL, Buenos Aires, 1984; BARRAGÁN, Ivonne, "La represión a la organización sindical de base en una fábrica estatal. La experiencia
El crecimiento de la productividad, en sectores como el automotriz, el autopartista, el de motores y otros, debe atribuirse no a la innovación tecnológica sino al desempleo, que se comenzó a notar a partir de 1979, y al aumento del ritmo de trabajo y de la duración de la jornada de trabajo, forzados por la coerción estatal y la recuperación del control patronal en las fábricas. ${ }^{11}$ Otro factor a tener en cuenta es el consentimiento y la colaboración de muchos trabajadores en la intensificación del trabajo. Es necesario estudiar sin prejuicios los motivos de ese comportamiento, tan poco considerado en la historia "heroica" de la resistencia obrera a la dictadura. ${ }^{12}$

Ante el golpe de estado y la caída del gobierno peronista, la respuesta de la mayoría de los trabajadores fue el repliegue, la parálisis y la pasividad. La ausencia de una movilización rápida y masiva es atribuible al desprestigio profundo del gobierno de Isabel Martínez de Perón, a las divisiones y disputas entre las

represiva de los trabajadores del Astillero Río Santiago durante la última dictadura militar.", ponencia presentada en IV Seminario Internacional Politicas de la Memoria: Ampliación del campo de los derechos humanos. Memoria $y$ perspectivas, Centro Cultural de la Memoria Haroldo Conti, Buenos Aires, 2011. Disponible en: <http:// conti.derhuman.jus.gov.ar/2011/10/mesa_1/barragan_ mesa_1.pdf>; DICÓSIMO, Daniel. “Indisciplina y consentimiento en la industria bonaerense durante la última dictadura militar. Los casos de Loma Negra Barker y Metalúrgica Tandil”, en Sociohistórica. Cuadernos del CISH, La Plata, 2008, № 23/24.

11. BECCARIA, Luis y YOGUEL, Gabriel, "Apuntes sobre la evolución del empleo industrial en el período 1973-1984", en Desarrollo Económico, Buenos Aires, 1988, V. XXVII, No 108.

12. DICÓSIMO, Daniel, “'La delgada línea roja’. Conflicto y consentimiento en las relaciones laborales (1976-83)", en Revista Historia Regional de la Sección Historia del Instituto Superior del Profesorado No 3 "Eduardo Lafferière", Villa Constitución, 2012, № 30. 
expresiones políticas y sindicales de la clase trabajadora, que se registraban ya antes del golpe militar: entre las diversas corrientes de izquierda y el peronismo ortodoxo, entre el clasismo y el sindicalismo de liberación de Agustín Tosco e, incluso, entre "rebeldes" y "verticalistas" dentro del sindicalismo peronista.

No obstante, en los sectores más calificados y organizados de la clase obrera, como el de la industria automotriz, el metalúrgico y el de las usinas eléctricas, las "medidas de fuerza" no desaparecieron completamente. ${ }^{13}$ Tres conflictos emblemáticos del segundo semestre de 1976 fueron el de Del Carlo (Metalúrgica Béccar), el de Ford Motors (General Pacheco) y de la empresa Servicios Eléctricos del Gran Buenos Aires (SEGBA) en la Ciudad de Buenos Aires. Esos episodios tienen algunos rasgos comunes con otros conflictos del período y nos permiten caracterizar la conflictividad en los primeros años del Proceso: sus protagonistas eran trabajadores calificados y con una larga tradición de organización sindical; las acciones que realizaron mostraban una creativa combinación de medidas de fuerza históricas con otras nuevas, adaptadas al contexto represivo.El conflicto podía expresarse abiertamente pero también pasar a los actos de sabotaje cuando las fuerzas de seguridad intervenían y golpeaban a los organizadores. Los hechos de protesta y reclamo tuvieron un alcance limitado a establecimientos aislados o a conjuntos locales o regionales; el motivo de los mismos era, en la mayoría de los casos, la defensa de la condición obrera ganada en los años anteriores al golpe de estado.

13. POZZI, Pablo, Oposición obrera a la dictadura, Contrapunto, Buenos Aires, 1988, p.71.
Estas características formaron parte de la primera etapa de los conflictos, que unos autores recortan desde el 24 de marzo de 1976 al 27 de abril de 1979 y otros la extienden a mediados del año 1981, por la primera huelga general en el primer caso y por los tempranos indicios de crisis del régimen, que obligaría a cambiar sus políticas hacia los trabajadores y el movimiento sindical, en el segundo caso. ${ }^{14} \mathrm{El}$ rasgo fragmentario, defensivo y no siempre abierto del conflicto en esta primera etapa puede atribuirse a varias razones, la más evidente es la intensidad y extensión inéditas de la represión. Otra razón es la decisión tomada por el Ministerio de Economía de anular las comisiones paritarias y otorgar a las empresas un margen de "flexibilidad" para decidir el nivel salarial de su mano de obra, lo cual trasladará la discusión al ámbito de las plantas fabriles. ${ }^{15}$

La principal motivación de los conflictos fue salarial, un $61,5 \%$ del total de casos contabilizados por Ricardo Falcón, pero hubo otras causas como las condiciones de trabajo y la falta o disminución del trabajo, 12,6\% y $11 \%$ respectivamente, y más lejos la defensa de la organización sindical, 7,4\%, el rechazo de las represalias patronales, $2,8 \%$, la defensa contra la represión estatal, 2,5\%, y los reclamos

14. FALCON, Ricardo, "La resistencia obrera a la dictadura militar (una reescritura de un texto contemporáneo a los acontecimientos)”, en QUIROGA, Hugo y TCACH, César (compiladores) $A$ veinte años del golpe. Con memoria democrática, Homo Sapiens Ediciones, Buenos Aires, 1996.

15. PALOMINO, Héctor, "Los cambios en el mundo del trabajo y los dilemas sindicales", en SURIANO, Juan (director) Dictadura y democracia (1976-2001), Colección Nueva Historia Argentina, Sudamericana, Buenos Aires, 2005; FALCÓN, Ricardo, "La resistencia obrera...”, Op. Cit.; BASUALDO, Victoria, "Complicidad patronal...", Op. Cit. 
en torno al comedor de planta, 2,2\%. Los tres primeros motivos pueden explicarse como una reacción a los esfuerzos del gobierno militar por estabilizar la economía. Como resultado de ese esfuerzo el salario real industrial cayó un 32\% sólo en el segundo trimestre de 1976, debido a la eliminación de todo control de precios y al congelamiento de los salarios, y se recuperó con un ritmo más lento en la manufactura que en otros sectores de la economía, probablemente porque el control salarial se aplicaba en forma más estricta en las diferentes ramas de la misma. ${ }^{16}$

En este período las formas del conflicto se adaptaron al contexto de fuerte represión. A las tradicionales huelgas, quites de colaboración, trabajo a reglamento y petitorios, se agregaron adaptaciones como el "trabajo a tristeza", la "huelga de la sopa", "aplaudidas" y otras. Estas formas adaptadas muestran algunas características comunes: corta duración, extensión limitada, permanencia en los lugares de trabajo y desarrollo intermitente. Resulta significativa la articulación de prácticas abiertas de protesta, como las huelgas, con los "conflictos no dirigidos", como los sabotajes. ${ }^{17}$ En el contexto de una represión

16. DIEGUEZ, Héctor y GERCHUNOFF, Pablo, "La dinámica del mercado laboral urbano en la Argentina, 1976-1981", en Desarrollo Económico, Buenos Aires, 1984, V.XXIV, p. 9.

17. DICOSIMO, Daniel y CARMINATI, Andrés, "Sabotaje a la dictadura. Un estudio de las formas de sabotaje industrial durante la última dictadura militar en el Gran Rosario y el Centro Sudeste bonaerense (1976-1983)", en Anuario IEHS, Tandil, 2013, № 28; CARMINATI, Andrés, "1978: reflujo, crisis y sabotaje. Conflictos obreros en el "Gran Rosario" durante la última dictadura militar", ponencia presentada en II Workshop Historia de las relaciones laborales en la Argentina del siglo XX, Rosario, 2012, p. 9; POZZI, Pablo, Oposición obrera..., Op. Cit., p. 81. salvaje y de un Estado que "interviene" en las relaciones laborales no ya para regularlas, como había ocurrido hasta 1976, sino para apoyar la recuperación y consolidación del control empresario sobre el proceso de trabajo, por ejemplo con la flexibilización salarial, la correlación de fuerzas se había vuelto desfavorable.

La vigencia de una nueva legislación laboral anti-obrera y la casi eliminación de las estructuras sindicales en la empresa, tuvieron como consecuencia la alteración de una de las formas del conflicto, el denominado "institucionalizado", es decir aquél que recibía algún reconocimiento institucional a través de un acuerdo formal o una práctica aceptada tradicionalmente, que no ha alcanzado el status de regla o norma. Ahora la institucionalización de un conflicto pasaba por la práctica consuetudinaria, informal, y ésta dependía de la estrategia empresaria y su evaluación de la coyuntura. El Estado ya no regulaba el conflicto sino que dejaba a los empresarios aplicar su voluntad y su conveniencia: en muchos casos de la negociación se pasaba a la represión y viceversa. Entonces el sabotaje se transformaba en algo parecido a lo que Edwards y Scullion denominan "conflicto no dirigido", es decir una conducta concreta que no es abiertamente conflictiva porque tiene como objeto ejercer presión pero no encuentra disponibles las instituciones formales que controlan, regulan y procesan los conflictos. ${ }^{18}$

En el año 1979, se observa una transición entre la primera etapa de conflictos "moleculares" y la segunda, que llegará hasta

18. EDWARDS, Paul y SCULLION, Hugh, La organización social del conflicto laboral. Control y resistencia en la fábrica, Ministerio de Trabajo y Seguridad Social, Madrid, 1982. 
1983, de centralización y coordinación nacional de las medidas de fuerza, a cargo de la Comisión Nacional de los 25 (CN 25), que luego adoptaría la denominación tradicional de CGT Brasil y finalmente de CGT República Argentina. A partir de fines de 1979, la economía real se deterioró sin pausa, debido a la reforma financiera de 1978 y el estímulo que la misma supuso para las importaciones, y al impacto destructivo de dos devaluaciones sucesivas, en abril y junio de 1981, lo que generó un incremento de los quebrantos y el desempleo. En ese contexto, el motivo de los conflictos experimentó un cambio: si bien el salarial siguió encabezando las estadísticas, como en el período anterior, a partir de 1980 aumentaron aquéllos causados por suspensiones y despidos debidos a la recesión y en defensa de las fuentes de trabajo. Mientras en el primer caso la forma de lucha era sacar el conflicto a la calle, con movilizaciones y concentraciones, que buscaban despertar la solidaridad de otros sectores, en el segundo fueron los tradicionales paros $\mathrm{y}$, en menor medida, la toma pacífica de las plantas.

\section{La resistencia en la historiografía sobre los trabajadores}

El comportamiento de la clase trabajadora durante la dictadura militar, y en particular los conflictos laborales, aparecieron como tema y problema en la historiografía con la recuperación de la Democracia. Este fue un momento de transición entre un campo que tradicionalmente se había ocupado del movimiento obrero, sus orientaciones políticoideológicas y sus dirigentes más notorios, y otro que pretendía relevar y comprender las experiencias de los trabajadores dentro y fuera del lugar de trabajo.

De esos primeros estudios, destacan los de Pablo Pozzi y Ricardo Falcón, ya citados en páginas anteriores, por su carácter pionero en el tratamiento del tema de la resistencia obrera y sindical. El primero de ellos tiene el mérito de haber adoptado un enfoque centrado en las prácticas "subterráneas" a nivel del lugar de trabajo, medidas de protesta y presión encubiertas, e introducido el interés por la experiencia de la resistencia como objeto de estudio. ${ }^{19} \mathrm{El}$ segundo es, al mismo tiempo, una valiosa síntesis de la conflictividad laboral del período 1976-1981, y un acercamiento a los actores, las motivaciones y las formas de los conflictos que se desarrollaron a un nivel micro, en los lugares de trabajo.

Durante la década de 1990 escasearon los estudios sobre este tema, pero tuvo lugar un fenómeno que los influiría más adelante: se constituyó el campo de la historia de los trabajadores, que tiene como objeto de estudio a los trabajadores como sujeto histórico. Este es recuperado por los historiadores al considerar las relaciones de producción y las tradiciones, sistemas de valores, ideas y formas institucionales que se originan de la experiencia en el escenario del cotidiano laboral. ${ }^{20}$ Desde el inicio del nuevo siglo, un número importante

19. El libro de Pozzi fue uno de los primeros, junto al de Arturo Fernández, en superar la tesis de la pasividad obrera, propuesta por Francisco Delich en 1982, según la cual una serie de factores (desregulación salarial, feroz represión, desocupación) hicieron de este el período de mayor desmovilización sindical desde 1955.

20. LOBATO, Mirta Zaida, La vida en las fábricas. Trabajo, protesta y política en una comunidad obrera, Berisso (1904-1970), Prometeo libros/Entrepasados, Buenos Aires, 2001. 
de artículos y ponencias, en comparación a la escasez anterior, fueron publicados o presentados en encuentros científicos. ${ }^{21}$

Los estudios de estos veinte años tienen en común varios elementos teóricometodológicos: comparten la preocupación por definir su objeto de estudio, los trabajadores, no ya desde categorías muy generales y homogéneas, sino a través del proceso por el cual se han constituido como un actor colectivo. Asimismo se observa un interés centrado, no en la construcción de síntesis, sino en recortes espaciales y temporales acotados a una región, ciudad, sector de producción o empresa, así como a una coyuntura o acontecimiento en particular. Por último, hay un esfuerzo por incorporar fuentes más o menos novedosas que, aunque controversiales como los documentos producidos por los organismos estatales de inteligencia y represión durante la dictadura, permitan superar los vacíos de información existentes.

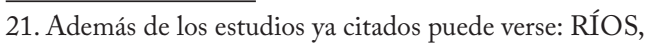
Sabrina, "Trabajadores durante la dictadura militar (1976-1983). Prácticas y memorias desde un estudio de caso", ponencia presentada en XI Jornadas Interescuelas / Departamentos de Historia, UNT, Tucumán, 2007;

DICÓSIMO, Daniel, "Experiencias productivas, visión del mundo y unidad obrera. El proceso de trabajo como dimensión explicativa de los conflictos laborales", en $H$-industria. Revista de historia de la industria argentina y latinoamericana, Buenos Aires, 2009, Año 3, No 4. Disponible en: $<$ http://ojs.econ.uba.ar/ojs/index. $\mathrm{php} / \mathrm{H}$-ind/article/view/454/837>) y DICÓSIMO, Daniel, "Dirigentes sindicales, racionalización y conflictos durante la última dictadura militar", en Entrepasados, Revista de Historia, Buenos Aires, 2006, No 29; SCHNEIDER, Alejandro, "Ladran Sancho...' Dictadura y clase obrera en la zona norte del Gran Buenos Aires", en POZZI, Pablo, CAMARERO, Hernán y SCHNEIDER, Alejandro (compiladores) De la Revolución Libertadora al Menemismo. Historia social y politica argentina, Imago Mundi, Buenos Aires, 2003.
En la mayoría de estos estudios, todas las medidas de fuerza en el lugar de trabajo y en las calles, como las huelgas, el "trabajo a reglamento" y tantas otras, ya fueran tradicionales o nuevas, han sido incluidas en el término resistencia. La amplitud del mismo pareciera tener la ventaja de desmitificar el fenómeno, si no lo hiciéramos ¿̇no caeríamos en una suerte de mitificación de los protagonistas de esas acciones?, ¿en considerar como héroes a quienes participaron de un conflicto o en oportunistas a los que aceptaron los beneficios de las prácticas paternalistas de algunas empresas?

Sin embargo, el uso del término no es tan inclusivo como parece: si bien en los estudios sobre el mundo del trabajo en este período el concepto no ha tenido nunca el carácter heroico que otras historiografías, como la francesa, le han atribuido, sí se ha privilegiado su uso para referirse a conductas activas de oposición a la dictadura y a las directivas unilaterales de las empresas. Tanto los que miraron el tema desde un enfoque contractualista e hicieron hincapié en la pérdida de derechos legales o adquiridos que sufrieron los trabajadores durante la dictadura, o los que adoptaron una perspectiva relacional del poder y se centraron en el reforzamiento del dispositivo disciplinario en el lugar de trabajo, han privilegiado la resistencia como reacción, contragolpe o, al menos, defensa activa. ${ }^{22}$

El predominio en los estudios históricos de las medidas de fuerza como sinónimos de esa oposición no es casual, ya que muchos de ellos no han considerado las actitudes pasivas de inconformismo o inadaptación al nuevo orden,

22. El trabajo de Ricardo Falcón podría situarse en el primer enfoque y el de Pablo Pozzi, en el segundo. 
y mucho menos se ha explorado si existió una "zona gris" entre la resistencia, entendida como contragolpe, y el consenso. Por "zona gris” nos referimos, valga la aclaración, a todo un espectro de conductas y actitudes que expresan rechazo, desacuerdo y desobediencia respecto de algunos de los principios y los métodos de la dictadura militar y de los empresarios pero, aún así, lo hacen de modo "discreto", no militante, ocasional y parcial, alternando con acuerdos, consentimientos e, incluso, identificación con otros aspectos del régimen. El objetivo de este artículo es reflexionar sobre estas cuestiones y proponer un enfoque analítico para aproximarnos a esa "zona gris" de la resistencia. Antes de presentar algunas preguntas y propuestas para orientar futuras investigaciones, daremos una rápida mirada sobre el carácter que se ha atribuido a la resistencia en la historiografía clásica y más reciente.

En los estudios históricos de los últimos treinta años no hay unanimidad sobre el carácter del fenómeno denominado "resistencia". Falcón considera que tuvo un carácter molecular y defensivo, reveló una gran capacidad de adaptación de la clase obrera, pero fue insuficiente para evitar un cercenamiento coyuntural profundo de la actividad sindical $\mathrm{y}$ una serie de modificaciones estructurales en su composición. ${ }^{23}$ Pozzi, a su vez, reconoce que los conflictos laborales del período fueron defensivos y reivindicativos, pero afirma que en otro plano tuvieron un profundo significado político porque impidieron a la gran burguesía monopólica resolver la crisis orgánica del capitalismo argentino $y$, por consiguiente, determinaron el fracaso del Proyecto de

23. FALCON, Ricardo, "La resistencia...", Op. Cit., p. 137.
Reorganización Nacional. En la dimensión específica de las fábricas, "la resistencia de los obreros representaba en efecto un desafío implícito a ciertos aspectos fundamentales de la organización de la producción capitalista; particularmente en lo que se refiere a la necesidad de readecuar el aparato económico a la concentración y la competencia internacional a través del aumento de la tasa de explotación”. ${ }^{24}$

En casi todos los estudios sobre la resistencia esta aparece como una serie de intentos, exitosos o fracasados, de construir un contra poder obrero en el espacio donde se impone el poder de la burguesía, el lugar de la producción. A nuestro modo de ver el análisis más elaborado y provocativo en ese sentido sigue siendo el de Pozzi, en las nociones de lucha por el control del proceso de trabajo y de relaciones de fuerza contrarias al poder. En su interpretación, el poder disciplinador del gobierno militar penetra hasta el espacio de la producción, donde refuerza las prácticas tayloristas de la Organización Científica del Trabajo (OCT), y es ahí donde se plantea una de las batallas más decisivas de la lucha de clases.

Las reivindicaciones levantadas por los obreros, señala Pozzi, trascienden lo salarial y apuntan contra aspectos centrales de la explotación del trabajo: la "prescindibilidad", la productividad, la autoridad del capataz, la organización sindical, etc. En particular el cuestionamiento a la autoridad del capataz revela la intención de desafiar el poder disciplinador de las empresas y luchar por el control del proceso de producción. En las luchas por el control de la producción se

24. POZZI, Pablo, Oposición obrera..., Op. Cit., p. 69. 
expresa el proyecto de sociedad de la clase obrera, no con un discurso explícito sino en forma embrionaria. Ese proyecto, sostiene Pozzi, tiene puntos de contacto "con un proyecto socialista”. En resumen, el control y la autodeterminación obreras sobre la producción fueron las formas en que se expresó un contra poder, una anti-disciplina, en las relaciones sociales de producción, que impediría a la dictadura militar resolver la crisis orgánica de la sociedad argentina.

En estudios más recientes, sigue vigente esta noción de la resistencia como un despliegue de fuerzas que se contraponen, en los lugares de trabajo, a las relaciones de poder que atraviesan tanto el dispositivo disciplinario como a los cuerpos de los trabajadores. A veces aparece implícita, supuesta, en los casos en que la resistencia no fue posible debido a una correlación negativa entre represión y organización sindical. Uno de esos estudios es el de Ivonne Barragán sobre el Astillero de Río Santiago (Ensenada), que reconstruye el entramado de la violencia estatal y para-estatal con una forma específica de organización del trabajo, propia de una empresa estatal. ${ }^{25}$ En dicho astillero se inició el mismo día del golpe de estado una larga serie de arrestos, secuestros y desapariciones, que lo llevaron a alcanzar el trágico récord de ser el establecimiento industrial con más desaparecidos de la Argentina. Un gran número de las víctimas pertenecían a las diferentes agrupaciones políticas y sindicales constituidas en el astillero en los primeros años setenta. La intensa represión fue complementada con un estricto control diario sobre los documentos y las pertenencias del personal, que realizaba una

25. Barragán ha presentado los resultados de su investigación en varios trabajos que ya citamos. Ver notas 3 y 10. guarnición militar permanente.

Si bien en los primeros trabajos de Barragán la ausencia de oposición obrera durante la dictadura es atribuida exclusivamente a la intensidad y alcance de la represión estatal y para-estatal, en textos más recientes la autora introduce otras dimensiones para interpretar ese comportamiento. En efecto, la estrategia empresarial parece haber sido un factor coadyuvante a la desaparición de los conflictos. La dirección del astillero, en la cual tenía importante participación la Marina de Guerra, combinaba la violencia explícita con acciones tendientes a la negociación y la cooperación con su personal obrero ya antes del golpe de estado. El antecedente más lejano de esa orientación es la construcción, en los primeros años setenta, de "una fuerte identificación de los trabajadores con la empresa a partir de una relación laboral beneficiosa en un contexto de fuerte ordenamiento jerárquico de la fuerza de trabajo, basada en una organización estamental por el nivel de capacitación técnica, tiempo de permanencia en la fábrica y de disciplina militarizada", lo cual "puede interpretarse como una modalidad del paternalismo industrial de rasgos peculiares". ${ }^{26}$

Sin embargo, el recurso de la coerción se volvió una tendencia creciente, en espejo con la dinámica del ciclo ampliado de conflicto protagonizado por sus trabajadores y por la aparición de agrupaciones sindicales combativas en el establecimiento. Entre 1975 y el 24 de marzo de 1976 la negociación y la cooperación se entremezclaron cada vez más con la violencia explícita, que terminaría condicionando no solo las negociaciones

26. BARRAGÁN, Ivonne, "Para el bien de...”, Op. Cit., p. 60. 
salariales sino la misma acción sindical posterior al golpe militar. La represión y el disciplinamiento descarnado, en el cual la vigilancia adquirió un rasgo extremo con la presencia de una guarnición militar permanente en el astillero, tuvieron como resultado la ausencia de conflictos entre 1976 y 1983.

Como señala Barragán, el grado de represión implementada en el Astillero de Río Santiago es un caso extremo en un marco represivo también extremo,pero esta evidencia no debería ser impedimento para buscar la manifestación de algún tipo resistencia por más "discreta” que fuera. Su conclusión de que fue imposible "la puesta en práctica de resistencias manifiestas o subalternas" puede atribuirse a las fuentes que ha consultado o que estaban disponibles para reconstruir dicho período. En sus trabajos los informes de la CONADEP predominan sobre los testimonios obtenidos en entrevistas y en los Juicios por la Verdad. O quizá se deba al supuesto de que sin la politización y la organización que florecieron en la primera parte de la década de 1970 era imposible la resistencia obrera. No obstante, aún en un contexto de desaparición o debilitamiento de la representación sindical, tanto oficial como alternativa, $y$ de fortalecimiento extremo de las estructuras disciplinarias, se puede suponer con un sustento conceptual que la clase obrera pudo haber recurrido a las prácticas, procedimientos y ardides "invisibles" que les permitieran resistir los ataques empresarios aún sin la capacidad estratégica que la politización había aportado unos pocos años antes.

De forma más o menos implícita, en algunos análisis ${ }^{27}$ está presente la concepción relacional

27. Ídem, p. 57; DICÓSIMO, Daniel, “Dirigentes 82 del poder de Foucault, según la cual el poder son relaciones de fuerza que producen a los sujetos, los dispositivos de poder prescriben conductas, adiestran los cuerpos y producen saberes. En las fábricas esos dispositivos actúan como un conjunto de métodos que permiten "el control minucioso de las operaciones del cuerpo, que garantizan la sujeción constante de sus fuerzas y les imponen una relación de docilidadutilidad...". ${ }^{28}$ La sujeción de los cuerpos es la violencia que, junto a la cooperación, requiere todo orden productivo; ${ }^{29}$ orden productivo que será la piedra clave de la "red variable de relaciones de fuerza que recorre la totalidad social" ${ }^{30}$ y en la que se apoya la dictadura militar para resolver la crisis orgánica del capitalismo argentino.

En la concepción foucaultiana la resistencia es inmanente al poder, "la resistencia y el poder se pertenecen mutuamente. El poder se pliega contra sí mismo, haciendo a la resistencia un elemento que lo constituye y hace posible, pero, por otro lado, que se contrapone a él." ${ }^{31} \mathrm{La}$ resistencia es una relación de fuerza que se opone activamente al poder dentro del orden productivo, es una lucha que busca abrir esos dispositivos, que los niega. ¿Pero qué pasa cuando esas relaciones de fuerza son tan poderosas que reducen

sindicales...", Op. Cit.

28. FOUCAULT, Michel, Vigilar y castigar. Nacimiento de la prisión, Siglo XXI, México, 1989, p. 141.

29. BARRAGÁN, Ivonne, "Para el bien de...”, Op. Cit., p. 57.

30. Juan Villarreal citado por POZZI, Pablo. Oposición obrera..., Op. Cit., p. 23.

31. DEL VALLE ORELLANA, Nicolás, "Entre poder y resistencia. Tras los rastros de la política en Foucault", en Revista Enfoques, Universidad Central de Chile, 2012, V.X, No 17, p. 162. 
a la lucha, que desorganizan y debilitan el poder de la resistencia? Si nos limitamos a ver la resistencia sólo como un contragolpe, es posible que esta se vuelva invisible en contextos de alto nivel de represión y bajo nivel de organización; pero quizá sea posible descubrirla si tenemos presente que Foucault la pensaba no sólo como contragolpe sino también como un "escape". Si el poder intenta captar los distintos elementos del quehacer social, la resistencia consiste en escapar a todo intento de captura. En consecuencia, será un movimiento que pretende hacer caso omiso y ubicarse al exterior del poder. ${ }^{32}$ "Escapa de algún modo a las relaciones de poder; algo que no es la materia prima más o menos dócil o reacia, sino que es el movimiento centrífugo, la energía inversa, la escapada”. ${ }^{33}$

La resistencia como "escape" no toma el carácter y la forma del conflicto laboral abierto sino el de la indisciplina o de la "infrapolítica", como la entiende James Scott: "una gran variedad de formas de resistencia muy discretas que recurren a formas indirectas de expresión". ${ }^{34}$ Entre las formas de la "infrapolítica" están el discurso oculto, los rumores, las bromas $\mathrm{y}$ otras, que constituyen acciones invisibles o apenas públicas realizadas en contextos de elevada coerción y donde las instituciones que canalizan y procesan los conflictos no existen o están momentáneamente clausuradas. Esa invisibilidad, señala Scott, es en buena medida resultado de una acción deliberada, de "una decisión táctica que está consciente

\section{2. Ídem, p. 163.}

33. FOUCAULT, Michel, Un diálogo sobre el poder y otras conversaciones, Alianza, Madrid, 2008, p. 93.

34. SCOTT, James, Los dominados y el arte de la resistencia, Era, México, 2004, p. 44. del equilibrio de poder". ${ }^{35}$ Esta noción es complementaria con la de "artes de hacer", propuesta por Michel de Certeau, que se refiere a las prácticas, procedimientos y ardides de quienes están "atrapados en las redes de la 'vigilancia", en las estructuras disciplinarias, y que tienden a crear dentro de las mismas un ambiente de "antidisciplina" que son su contrapartida. En un equilibrio de poder desfavorable y en un espacio que ha sido reconquistado por el otro, la táctica "no cuenta con la posibilidad de darse un proyecto global ni de totalizar al adversario en un espacio distinto, visible y capaz de hacerse objetivo."... "Este no lugar le permite, sin duda, la movilidad, pero con una docilidad respecto a los azares del tiempo, para tomar al vuelo las posibilidades que ofrece el instante"... "En suma, la táctica es un arte del débil”. ${ }^{36}$

Vale aclarar que lo dicho hasta aquí no equivale a considerar que en el mundo real del trabajo las actitudes propias del contragolpe o del escape se manifestaron separadas unas de otras, ni que el observador podrá encontrarlas aisladas y claramente diferenciadas entre sí. Por el contrario, lo común será que coexistan, se combinen y complementen en un mismo episodio de resistencia, por ejemplo es posible que los sabotajes de autor individual sean parte de un mismo proceso de conflictos colectivos. Lo que se propone aquí es una "disección" conceptual, una separación sólo válida en el orden conceptual, de actitudes que en la realidad histórica forman parte de procesos dinámicos y complejos.

35. Ibídem.

36. DE CERTEAU, Michel, La invención de lo cotidiano. 1. Artes de hacer, Universidad IberoamericanaInstituto Tecnológico y de Estudios Superiores de Occidente-Centro Francés de Estudios Mexicanos y Centroamericanos, México, 1996, pp. 54-55. 
Por otra parte, el carácter de la resistencia se vuelve difuso y ambiguo cuando aparece en espacios productivos organizados según programas de incentivación del trabajo, a través de diversos medios como las primas y otros, que tenían el consentimiento de los trabajadores. En esos casos, éstos desarrollaban un interés particular por la continuidad de los mismos, basado tanto en los beneficios económicos del aumento de la productividad como en una serie de valores derivados de la experiencia del taller, como el aprecio por la destreza y la resistencia física, el cumplimiento de metas, el orgullo de dominar los secretos de operaciones en apariencia simples, entre otros. La participación en este tipo de trabajo se convertía en un fin en sí mismo y, como ha señalado Michel Burawoy, generaba un espacio de acuerdo con la empresa respecto a las pautas de aumento de la productividad. ${ }^{37}$

No obstante, esto no significaba otorgar consenso a la apropiación del trabajo no retribuido por los empresarios, lo que marca la diferencia entre consentimiento y consenso, ni para introducir cambios unilaterales en los programas de incentivos. Por el contrario, el conflicto reaparecía cada vez que los trabajadores involucrados veían disminuir su control sobre las condiciones que les permitía cumplir las cuotas complementarias y obtener las primas correspondientes. Para comprender la ambigüedad existente en este comportamiento nos referiremos brevemente a un caso que hemos estudiado para nuestra tesis doctoral y sobre el que escribimos en varias oportunidades: el de los trabajadores y

37. BURAWOY, Michael, El consentimiento en la producción. Los cambios del proceso productivo en el capitalismo monopolista, Ministerio de Trabajo y Seguridad Social, Madrid, 1989.

84 los conflictos de la fábrica Metalúrgica Tandil, una fundidora de autopartes "cautiva" de Renault Argentina. ${ }^{38}$

En dicho establecimiento los programas de incentivos con cuotas complementarias y primas habían sido introducidos en las secciones de fusión, noyería y moldeo ya en 1956, cuatro años antes que se institucionalizaran en el Convenio Colectivo de Trabajo de la industria metalúrgica de 1960. En el año 1978, la empresa redujo en la sección noyería la aplicación de un régimen de seis horas y plus salarial por insalubridad a sólo dos puestos de trabajo, que habían impuesto los trabajadores en 1975, restaurando la jornada laboral de ocho horas para el resto. El sindicato propuso cumplir el horario habitual y permanecer en el puesto de trabajo el tiempo restante, pero los noyeros decidieron parar por tiempo indeterminado. Durante el mes de julio de 1978, éstos se mantuvieron en la sección sin trabajar y cuando les prohibieron ingresar a la planta se reunieron en la puerta de entrada. El 2 de agosto, ante el rumor de que la empresa despediría a una parte de los operarios en conflicto, la mayoría aceptó el nuevo horario a cambio de un plus salarial del $20 \%$. Un grupo de veinticinco operarios lo rechazaron y fueron despedidos por "inadaptación” al nuevo régimen laboral.

Al declararse el conflicto no había unanimidad entre los noyeros sobre la validez del régimen de jornada reducida, debido a la diversidad de condiciones y medio ambiente

38. Presentamos este caso extensamente en DICÓSIMO, Daniel, “La delgada línea roja...”, Op. Cit. (Este artículo fue reproducido en el dossier on line del Programa Inter Universitario de Historia Política coordinado por Daniel Lvovich: <http://www. historiapolitica.com/dossier/ actitudes-sociales-dictadura $>$ ). 
de trabajo que predominaba en la sección y a la percepción de los trabajadores sobre la justicia de la retribución que recibían por exponerse al riesgo. El subproceso de noyería había sido modernizado entre 1958 y 1974, al convertirse Metalúrgica Tandil en una "fundición cautiva" de Industrias Kaiser Argentina primero y de Renault Argentina después. Se incorporaron máquinas para elaborar noyos según el sistema de "caja caliente", cuyas materias primas liberaban gases agresivos al momento de la cocción, como el fenol -su componente de formaldehído afectaba el organismo humano-. Las tareas de preparado y ensamble de noyos, a su vez, fueron redistribuidas alrededor de varias líneas, situadas en un sector apartado respecto a la "línea de caja caliente", donde las condiciones ambientales eran distintas. E1 trabajo en esos sectores presentará a partir de entonces diferencias en cuanto a la carga laboral y a las condiciones ambientales.

En la "línea de caja caliente", servían máquinas con control eléctrico, el operador se encargaba de iniciar e interrumpir el ciclo de las mismas y de algunas tareas auxiliares, como introducir la caja de noyos a la máquina y luego trasladarla a una cinta transportadora; el ciclo automático de la máquina no era regulado por éste e imprimía un ritmo veloz a las tareas complementarias. La carga de trabajo aumentaba por la incidencia de la radiación (calor) que despedían las cajas de noyos y la contaminación ambiental (formaldehído). En la "línea de preparado y ensamble de noyos", en cambio, las tareas eran más aliviadas, porque los operarios no movían cajas, ya que trabajaban en las piezas que llegaban sobre una cinta transportadora, y estaban expuestos a una menor incidencia de contaminación y ruidos, y no existían vibraciones ni radiación. ${ }^{39}$

No obstante, es necesario para comprender la resistencia inicial a la directiva empresaria tener presente que aquélla no se basaba en los efectos residuales sobre la salud, sino en sus resultados económicos. Los operarios que lideraron el conflicto integraban los programas de incentivación al trabajo e, inesperadamente, advertían que los cambios en el régimen laboral alteraban su acuerdo con la empresa respecto a los beneficios de la remuneración con primas. Es decir que el principal motivo del conflicto no era el nuevo horario, inaceptable porque perjudicaría la salud de los trabajadores a largo plazo, sino la disminución del control obrero sobre las condiciones que permitían cumplir las cuotas complementarias y obtener las primas correspondientes. En resumen, había aumentado la incertidumbre sobre el resultado del trabajo a destajo. ${ }^{40}$

La decisión empresaria ponía en duda la capacidad de los maquinistas para alcanzar las metas previstas, porque implicaba una sobre exigencia física y disminuía las posibilidades de recuperación de energía muscular. La resistencia física y mental se veía afectada con la prolongación de la jornada de seis a ocho horas, y con la extensión a nueve horas a partir de 1980, no porque los noyos fueran pesados sino por una exposición más prolongada a la

39. Testimonio de Oscar Piñón, operador en la "línea de caja caliente", 1988. Pericia técnica sobre las "líneas de caja caliente" y de "preparado y ensamble de noyos" realizada en 1979, en Tribunal del Trabajo de Tandil, "Hernández Carlos y otros contra Metalúrgica Tandil sobre cobro de haberes", 1980, folios 190-207.

40. Según Buroway, la incertidumbre que ocasionan los cambios en la organización del trabajo es un importante motivo de conflicto en los talleres incentivados. BURAWOY, Michael, El consentimiento..., Op. Cit., p. 114. 
temperatura y el gas que emitían las máquinas. Como denunciaba el sindicato ante el Ministerio de Trabajo, estos cambios obligarían a "un esfuerzo físico sobrehumano, máxime considerando que muchas de las secciones rozan el límite de lo insalubre...". ${ }^{41}$ La protesta, entonces, no representaba una impugnación de la naturaleza capitalista del trabajo en la industria ni un reclamo consecuente por el perjuicio causado a la salud de los trabajadores, que fue acallado con el otorgamiento de un adicional al salario, sino una reafirmación del interés de los trabajadores por participar de los programas de trabajo por primas y de lo que consideraban su derecho a negociar sus pautas con la empresa.

Por último, un espacio laboral donde la resistencia es esquiva y tan ambigua como en el anterior lo constituyen aquellas fábricas organizadas y administradas según los principios y las prácticas del paternalismo industrial. En oportunidad de un atentado contra un horno en la fábrica Loma Negra de Olavarría, en febrero de 1979, el informe policial retrataba la aparente "paz social" reinante en la misma:

En los casi 40 años de existencia de la empresa nunca existió un conflicto laboral, posiblemente el origen de este hecho de por sí extraordinario se encuentre en las condiciones excepcionales ofrecidas por la firma, dado que no sólo perciben muy buenos salarios, que en todo caso se encuentran entre los mejores del país, sino que existen una serie de ventajas accesorias para el empleado, tales como atención

41. Nota de la Unión Obrera Metalúrgica, seccional Tandil, al Ministerio de Trabajo, delegación Tandil, en Tribunal del Trabajo de Tandil, "Indemnización por despido, Romero Néstor y otros contra Metalúrgica Tandil", 1980. médica integral sin cargo, proveeduría al costo, transporte gratuito, en muchos casos vivienda y electricidad sin cargo, becas para los hijos del personal que estudian, clubes y asistencia social en general. Como dato ilustrativo debemos señalar que de los 38 ingenieros que trabajan en la planta de Loma Negra, la mayoría son hijos de obreros de la empresa... Es notable la identificación total del personal con la empresa, a punto tal que podría decirse que siente a la misma un poco como cosa propia y viven en el sentido amplio del términos los aciertos y el progreso, así como sufren y realmente se preocupan por los problemas e inconvenientes. ${ }^{42}$

Es probable que el diagnóstico policial haya sido dictado por la misma empresa, que ha terminado creyendo ciegamente en su propio discurso sobre la "gran familia" que ha constituido con su plantel de obreros, empleados e ingenieros. En el mismo aparece, además, una interpretación del sabotaje como conflicto, pero ¿de qué conflicto está hablando la empresa?, veamos otra cita del informe policial:

Si bien no queda margen de duda de que se trata de un hecho intencional (aún admitiendo como posibilidad que el hecho narrado se haya producido por efectos de la vibración normal de funcionamiento) resulta difícil identificar a él o los autores, como asimismo sus móviles, ya que la empresa abona salarios superiores a los fijados por el Estado; contempla situaciones de tipo familiar, casos de asistencia médica especial o de urgencia a esposa e hijos de trabajadores, que son llevados a Capital Federal por cuenta de la empresa; construye barrios de vivienda, etc. Tampoco existen o se han producido medidas que pudieran

42. Comisión Provincial por la Memoria, Archivo DIPPBA, Mesa B, Carpeta 86, Legajo 89, folio 92. 
crear resentimientos entre el personal, pues si bien hace algún tiempo hubo algunos despidos, se trató de elementos considerados perturbadores, y se les abonó la indemnización que correspondía a cada caso... Solo cabe pensar que ha sido un operario movido por razones puramente personales, derivadas de algún resentimiento producto de una mente anormal. ${ }^{43}$ (La cursiva es nuestra).

Como vemos, en el discurso paternalista el conflicto es percibido como algo extraño y ajeno a la comunidad laboral, a la "gran familia", y su origen, producto del resentimiento de "una mente anormal", es de naturaleza psicológica e individual: ni el colectivo obrero ni el sindicato aparecen como partes reconocibles del conflicto.

El paternalismo industrial suele elaborar la imagen de sus establecimientos como una comunidad cerrada y amenazada por peligros externos, ante la cual las fuentes sindicales y los testimonios orales pueden servirnos para indagar debajo de esa superficie aparentemente tranquila. ${ }^{44}$ Son necesarios algunos recaudos, porque los sindicatos de las ramas donde predominaba esta forma de organizar el trabajo, como la textil o la del cemento, siguieron cooptados por la patronal o fueron marginados del "sistema de fábrica con villa obrera” y perdieron ascendiente, más allá de los servicios sociales, sobre sus afiliados. ${ }^{45} \mathrm{De}$ cualquier forma el sabotaje es uno de los cabos sueltos que asoma en ese mundo idealizado de la "gran familia" y no podemos menospreciarlo

\section{Ibídem.}

44. NEIBURG, Federico, Fábrica y Villa Obrera: historia social y antropología de los obreros del cemento, CEAL, Buenos Aires, 1988.

45. DICÓSIMO, Daniel, “Indisciplina y...”, Op. Cit. como indicador de las tensiones y los conflictos que la agitaban.

El sabotaje durante la última dictadura ha sido poco estudiado en comparación a otras formas del conflicto; el libro de Pozzi es pionero en considerarlo una de las múltiples formas de la resistencia. En un artículo de reciente publicación, con Andrés Carminati hemos reconstruido una serie de sabotajes, correspondientes a las regiones del "cordón industrial del Paraná” y del centro-sudeste bonaerense, específicamente Tandil, Olavarría y Barker. ${ }^{46}$ Siguiendo la conceptualización de Paul Edwards y Hugh Scullion, diferenciamos a los sabotajes de la mayoría de las medidas de fuerza, como huelgas, quites de colaboración, etc., porque en estos casos, que denominamos "conflictos abiertos", el conflicto es reconocido por todos los participantes y se toma una acción para expresarlo, mientras que en los sabotajes, clasificados como "conflictos no dirigidos", hay una conducta concreta pero ésta no es abiertamente conflictiva, o sea no hay motivos ni autores explícitos. ${ }^{47}$

El sabotaje es una de las formas más importantes de los "conflictos no dirigidos" y, al mismo tiempo, una de las más difíciles de analizar, debido al sesgo con que las fuentes lo mencionan: expresión de una resistencia heroica para las publicaciones militantes, ecos de la amenaza de la "guerrilla industrial" para los periódicos comerciales, registro de la preocupación patronal por la persistencia de elementos "perturbadores" para la producción en los informes policiales, escaso

46. DICÓSIMO, Daniel y CARMINATI, Andrés, "Sabotaje a la dictadura...", Op. Cit.

47. EDWARDS, Paul y SCULLION, Hugh, $L a$ organización social..., Op. Cit. 
reconocimiento en los testimonios obreros, etc. ¿Qué significa el sabotaje en este período? ¿Fue un instrumento desesperado e ineficaz para debilitar el orden capitalista y autoritario? ¿Acaso una forma de presión o de expresión del descontento hacia los empresarios?

Teniendo en cuenta las dificultades teóricas y empíricas para caracterizarlo es importante tener en cuenta el contexto en el que se produce, entendiendo por este no solo la particular organización del trabajo de la fábrica o el taller, sino también la coyuntura política, social y económica y la estructura social, en particular lo que concierne a las relaciones sociales y a la organización sindical vigentes en el lugar de trabajo. Los sabotajes no expresaron sentimientos de frustración o desesperación, originados en la incapacidad para adaptarse al sistema industrial, como quisieron interpretarlas los enfoques funcionalistas $\mathrm{y}$ conductistas sobre el conflicto en los países industrializados de la segunda posguerra, ${ }^{48}$ sino formas de acción sindical alternativas a las que habían sido propias del conflicto abierto e institucionalizado, antes del golpe de estado de 1976.

En todos los establecimientos que estudiamos las comisiones internas y los cuerpos de delegados habían sido desconocidos abierta o tácitamente por las empresas y advertidos

48. Una visión panorámica sobre estos enfoques en MONTES CATÓ, Juan, "Dominación en los lugares de trabajo y formas de expresión del conflicto: las nuevas generaciones de trabajadores frente a las políticas manageriales", ponencia presentada en XXVI Congreso de la Asociación Latinoamericana de Sociologia, Guadalajara, México, 2007. Disponible en: <http://www. researchgate.net/publication/266492690_Dominacin en_los_espacios_de_trabajo_y_formas_de_expresin_del_ conflicto_las_nuevas_generaciones_de_trabajadores_ frente_a_las_polticas_manageriales>

88 brutalmente por el ejército sobre su nuevo y limitado papel de administradores de las obras sociales por el ejército. Al mismo tiempo, el gobierno de facto eliminaba o suspendía las normas que habían permitido hasta entonces poner en práctica procesos de regulación, control y resolución de los conflictos. En estos casos el sabotaje representaba una forma de conflicto alternativo a los "abiertos", a través de la cual activistas en grupo o individualmente adaptaban sus acciones al cierre de los canales institucionales, formales e informales.

Llegados a este punto queremos plantear algunas preguntas, que surgen del análisis anterior y que podrían servir para orientar la exploración de la "zona gris", entre la resistencia, entendida como contragolpe, y el consenso. Una lista provisoria sería la siguiente:

1. ¿La correlación entre nivel de la represión estatal y posibilidad de organización colectiva limita drásticamente la resistencia?, ¿cómo descubrir, identificar y comprender las conductas no consensuales y, a la vez, poco explícitas, en los espacios laborales con un alto nivel de represión y un bajo nivel de organización sindical? En otras palabras, ¿qué estrategia de búsqueda debemos seguir cuando las relaciones de fuerza en un establecimiento han sido tan poderosas que reducen a la lucha, que desorganizan y debilitan el poder de la resistencia?

2. ¿Es legítimo considerar al "escape" como una forma de resistencia? ¿Cuál es la mejor forma de detectarlo y reconstruir sus formas? En otras palabras, ¿cómo podemos distinguir la indisciplina como resistencia de la que no tenía 
ese propósito? ¿El sabotaje puede ser considerado en todos los casos una forma de resistencia? ¿Es posible comprenderlo adecuadamente sin introducir el análisis de la organización del trabajo en cada establecimiento?

3. ¿La resistencia puede surgir de la "obediencia condicionada" que implica el consentimiento a las formas capitalistas de organizar la producción? ¿Cómo detectar la "incertidumbre" en el trabajo, que estaría en el límite entre consentimiento y resistencia?

4. ¿Es posible la resistencia en el contexto de una organización laboral paternalista? ¿Qué nos dicen las formas "discretas" de resistencia, como el sabotaje, sobre la identidad de los trabajadores de esos espacios laborales?

\section{Conclusiones}

En la historiografía sobre los trabajadores de los últimos treinta años se ha privilegiado el uso del término resistencia para referirse a conductas activas de oposición a la dictadura y a las directivas unilaterales de las empresas. En muchos casos, la resistencia implica reacción, contragolpe o, al menos, defensa activa. Por lo general no han considerado las actitudes pasivas de inconformismo o inadaptación al nuevo orden, y mucho menos se ha explorado si existió una "zona gris" entre la resistencia activa y el consenso.

Una influencia determinante sobre esas interpretaciones ha sido la de Pozzi, en cuyo estudio clásico la resistencia aparece como una serie de intentos, exitosos o fracasados, de construir un contra poder obrero en el espacio donde se impone el poder de la burguesía, el lugar de la producción. En textos recientes, y no tanto, puede apreciarse la concepción relacional del poder de Foucault, según la cual el poder son relaciones de fuerza que producen a los sujetos, los dispositivos de poder prescriben conductas, adiestran los cuerpos y producen saberes. Dicha perspectiva supone que la resistencia es inmanente al poder, es una relación de fuerza que se opone activamente al poder dentro del orden productivo, es una lucha que busca abrir los dispositivos disciplinarios, que los niega.

El problema de este enfoque, cuando se centra exclusivamente en la resistencia como la "otra cara" del poder, es que no puede aprehender ni explicar las actitudes no consensuales cuando esas relaciones de fuerza son tan poderosas que debilitan la lucha, que desorganizan y debilitan el poder de los trabajadores. En otras palabras, si nos limitamos a ver la resistencia solo como un contragolpe, es posible que esta se vuelva invisible en contextos de alto nivel de represión y bajo nivel de organización. Asimismo, el carácter de la resistencia se vuelve difuso y ambiguo cuando lo buscamos desde esa perspectiva en espacios productivos organizados según programas de incentivación del trabajo, a través de diversos medios como las primas y otros, que tenían el consentimiento de los trabajadores, y en otros administrados según los principios y las prácticas del paternalismo industrial.

El desafío de los historiadores es, por lo tanto, ampliar el concepto de resistencia para incorporar un amplio espectro de conductas y actitudes que, más allá de participar ocasionalmente en la construcción 
de un contrapoder, expresaban rechazo, desacuerdo y desobediencia de un modo "discreto", ocasional y parcial, alternando con acuerdos y consentimientos. Un conjunto de comportamientos situado en un ámbito cotidiano y anónimo, que estaba muy cerca de la "inadaptación" a las reglas del trabajo industrial y cuya naturaleza conflictiva era, como consecuencia, ignorada por los estudios históricos. Estas conductas y actitudes, que posiblemente fueron propias de la mayoría de los trabajadores, también deberían ser consideradas legítimamente como parte de la resistencia.<smiles>C=CC=[Te]=CC</smiles>

Recibido: 27- 03-2015

Aceptado: 31- 08-2015

Publicado: 21-12-2015 


\section{Bibliografía}

ABÓS, Álvaro, Las organizaciones sindicales y el poder militar (1976-83), CEAL, Buenos Aires, 1984.

ÁGUILA, Gabriela, Dictadura, represión y sociedad en Rosario, 1976/1983. Un estudio sobre la represión y los comportamientos y actitudes sociales en dictadura, Prometeo, Buenos Aires, 2008.

BASUALDO, Victoria y LORENZ, Federico, "Trabajadores en la década del setenta en Argentina: perspectivas y propuestas a partir de dos estudios de caso", ponencia presentada en X Jornadas Interescuelas y Departamentos de Historia, Rosario, 2005.

BASUALDO, Victoria, "Complicidad patronal-militar en la última dictadura argentina: los casos de Acindar, Astarsa, Dálmine-Siderca, Ford, Ledesma y Mercedes Benz”, en Suplemento especial Revista Engranajes, Buenos Aires, 2006, No 5, FETIA.

BARRAGÁN, Ivonne, "La represión a la organización sindical de base en una fábrica estatal. La experiencia represiva de los trabajadores del Astillero Río Santiago durante la última dictadura militar.”, ponencia presentada en IV Seminario Internacional Políticas de la Memoria: Ampliación del campo de los derechos humanos. Memoria y perspectivas, Centro Cultural de la Memoria Haroldo Conti, Buenos Aires, 2011. Disponible en: <http://conti.derhuman.jus.gov.ar/2011/10/mesa_1/barragan_mesa_1.pdf>

BARRAGÁN, Ivonne, "Para el bien de la Nación. Gestión militar de empresas estatales, prácticas de integración y represión de la fuerza de trabajo desde la perspectiva de caso. El Astillero Río Santiago, 1973-1976”, en Avances del Cesor, Rosario, 2013, No 10. Disponible en: <http://web2.rosario-conicet. gov.ar/ojs/index.php/AvancesCesor/article/view/v10a03>

BECCARIA, Luis y YOGUEL, Gabriel, "Apuntes sobre la evolución del empleo industrial en el período 1973-1984”, en Desarrollo Económico, Buenos Aires, 1988, V. XXVII, 1988, No 108, pp. 589-605.

BITRÁN, Rafael y SCHNEIDER, Alejandro, "Dinámica social y clase trabajadora durante la dictadura militar de 1976-1983. Estudio de la zona norte del Gran Buenos Aires en particular de las fábricas Del Carlo y Ford Motors", en RODRÍGUES, Leoncio Martins y otros, Nuevas tendencias en el sindicalismo: Argentina y Brasil, Biblos - Simón Rodríguez, Buenos Aires, 1992.

BURAWOY, Michael, El consentimiento en la producción. Los cambios del proceso productivo en el capitalismo monopolista, Ministerio de Trabajo y Seguridad Social, Madrid, 1989.

CARMINATI, Andrés, “1978: reflujo, crisis y sabotaje. Conflictos obreros en el "Gran Rosario” durante la última dictadura militar”, ponencia presentada en II Workshop Historia de las relaciones laborales en la Argentina del siglo XX, Rosario, 2012.

CIEZA, Daniel, El componente anti sindical del Terrorismo de Estado, Cuadernos del Archivo Nacional de la Memoria No 3, Ministerio de Justicia y Derechos Humanos de la Nación, Buenos Aires, 2012.

DE CERTEAU, Michel, La invención de lo cotidiano. 1. Artes de hacer, Universidad IberoamericanaInstituto Tecnológico y de Estudios Superiores de Occidente-Centro Francés de Estudios Mexicanos y Centroamericanos, México, 1996. 
DEL VALLE ORELLANA, Nicolás, "Entre poder y resistencia. Tras los rastros de la política en Foucault”, en Revista Enfoques, Universidad Central de Chile, 2012, V. X, No 17, pp. 147-168.

DICÓSIMO, Daniel, "Dirigentes sindicales, racionalización y conflictos durante la última dictadura militar”, en Entrepasados, Revista de Historia, Buenos Aires, 2006, No 29, pp. 87-105.

DICÓSIMO, Daniel. "Indisciplina y consentimiento en la industria bonaerense durante la última dictadura militar. Los casos de Loma Negra Barker y Metalúrgica Tandil”, en Sociohistórica. Cuadernos del CISH, La Plata, 2008, No 23/24, pp. 13-37.

DICÓSIMO, Daniel, "Experiencias productivas, visión del mundo y unidad obrera. El proceso de trabajo como dimensión explicativa de los conflictos laborales", en $H$-industria. Revista de historia de la industria argentina y latinoamericana, Buenos Aires, 2009, Año 3, No 4. Disponible en: <http://ojs.econ.uba.ar/ ojs/index.php/H-ind/article/view/454/837>.

DICÓSIMO, Daniel, “'La delgada línea roja'. Conflicto y consentimiento en las relaciones laborales (197683)”, en Revista Historia Regional de la Sección Historia del Instituto Superior del Profesorado No 3 "Eduardo Lafferière", Villa Constitución, 2012, No 30.

DICOSIMO, Daniel y CARMINATI, Andrés, "Sabotaje a la dictadura. Un estudio de las formas de sabotaje industrial durante la última dictadura militar en el Gran Rosario y el Centro Sudeste bonaerense (1976-1983)", en Anuario IEHS, Tandil, 2013, No 28, pp. 257-278.

DIEGUEZ, Héctor y GERCHUNOFF, Pablo, "La dinámica del mercado laboral urbano en la Argentina, 1976-1981”, en Desarrollo Económico, Buenos Aires, 1984, V. XXIV, pp. 3-40.

EDWARDS, Paul y SCULLION, Hugh, La organización social del conflicto laboral. Control y resistencia en la fábrica, Ministerio de Trabajo y Seguridad Social, Madrid, 1982.

FALCÓN, Ricardo, "La resistencia obrera a la dictadura militar (una reescritura de un texto contemporáneo a los acontecimientos)”, en QUIROGA, Hugo y TCACH, César (compiladores) A veinte años del golpe. Con memoria democrática, Homo Sapiens Ediciones, Buenos Aires, 1996.

FERNÁNDEZ, Arturo, Las prácticas sociales del sindicalismo, Centro Editor de América Latina, Buenos Aires, 1984.

FOUCAULT, Michel, Vigilar y castigar. Nacimiento de la prisión, Siglo XXI, México, 1989.

FOUCAULT, Michel, Un diálogo sobre el poder y otras conversaciones, Alianza, Madrid, 2008.

GRESORES, Gabriela, "Conflictos obreros en la industria frigorífica bajo la dictadura militar: La huelga larga de Swift de Berisso”, en Ciclos, Buenos Aires, 2001, Año XI, V. IX, No 22.

LOBATO, Mirta Zaida, La vida en las fábricas. Trabajo, protesta y politica en una comunidad obrera, Berisso (1904-1970), Prometeo libros/Entrepasados, Buenos Aires, 2001, pp. 87-108.

LORENZ, Federico, Los zapatos de Carlito. Una historia de los trabajadores navales de Tigre en la década del 
setenta, Norma, Buenos Aires, 2007.

MONTES CATÓ, Juan, "Dominación en los lugares de trabajo y formas de expresión del conflicto: las nuevas generaciones de trabajadores frente a las políticas manageriales", ponencia presentada en $X X V I$ Congreso de la Asociación Latinoamericana de Sociología, Guadalajara, México, 2007. Disponible en: <http://www.researchgate.net/publication/266492690_Dominacin_en_los_espacios_de_trabajo_y_ formas_de_expresin_del_conflicto_las_nuevas_generaciones_de_trabajadores_frente_a_las_polticas_ manageriales>.

NEIBURG, Federico, Fábrica y Villa Obrera: historia social y antropología de los obreros del cemento, CEAL, Buenos Aires, 1988.

NOVARO, Marcos y PALERMO, Vicente, La dictadura militar 1976-1983. Del golpe de Estado a la restauración democrática, Paidós, Buenos Aires, 2003.

O’ DONNELL, Guillermo, Modernización y autoritarismo, Paidós, Buenos Aires, 1972.

PALOMINO, Héctor, "Los cambios en el mundo del trabajo y los dilemas sindicales”, en SURIANO, Juan (director) Dictadura y democracia (1976-2001), Colección Nueva Historia Argentina, Sudamericana, Buenos Aires, 2005.

POZZI, Pablo, Oposición obrera a la dictadura, Contrapunto, Buenos Aires, 1988.

RÍOS, Sabrina, "Trabajadores durante la dictadura militar (1976-1983). Prácticas y memorias desde un estudio de caso", ponencia presentada en XI Jornadas Interescuelas / Departamentos de Historia, Universidad Nacional de Tucumán, Tucumán, 2007.

SCOTT, James, Los dominados y el arte de la resistencia, Era, México, 2004.

SIMONASSI, Silvia, "Productividad y disciplina en las fábricas metalúrgicas del Gran Rosario: Una mirada desde el periódico de la Asociación de Industriales Metalúrgicos de Rosario, 1974-1981”, en Papeles de trabajo, Rosario, 1996, № 3.

SIMONASSI, Silvia, "Conflictividad laboral y políticas disciplinarias en la industria metalúrgica de la ciudad de Rosario, 1973-1976”, en Anuario IEHS, Tandil, 2007, No 22, pp. 465-486.

SCHNEIDER, Alejandro, “'Ladran Sancho...' Dictadura y clase obrera en la zona norte del Gran Buenos Aires", en POZZI, Pablo, CAMARERO, Hernán y SCHNEIDER, Alejandro (compiladores) De la Revolución Libertadora al Menemismo. Historia social y politica argentina, Imago Mundi, Buenos Aires, 2003. 